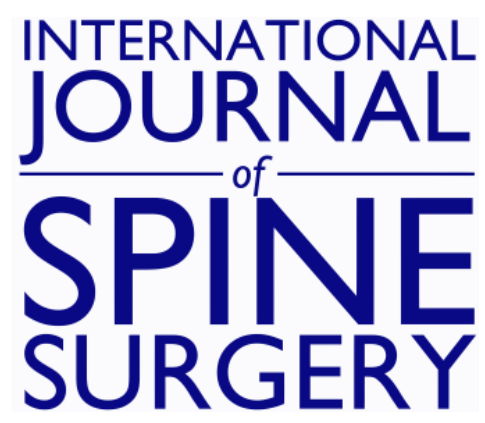

\title{
Validation and Analysis of a Multi-site MIS Prospective Registry Through Sub-analysis of an MIS TLIF Subgroup
}

Joseph A. Sclafani, Kamshad Raiszadeh, Ramin Raiszadeh, Paul Kim, Todd Doerr, Farhan Siddiqi, Ivan LaMotta, Paul Park, Cary Templin, Sandeep Gill, Kevin Liang and Choll W. Kim

Int J Spine Surg 2014, 8 ()

doi: https://doi.org/10.14444/1004

http://ijssurgery.com/content/8/4

This information is current as of April 26, 2023.

Email Alerts Receive free email-alerts when new articles cite this article. Sign up at:

http://ijssurgery.com/alerts

The International Journal of Spine Surgery

2397 Waterbury Circle, Suite 1,

Aurora, IL 60504, Phone: +1-630-375-1432 


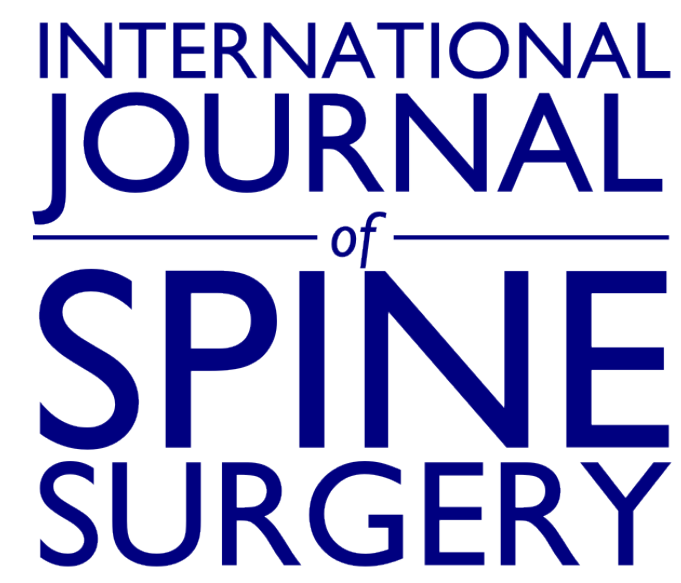

This article generously published free of charge by the International Society for the Advancement of Spine Surgery.

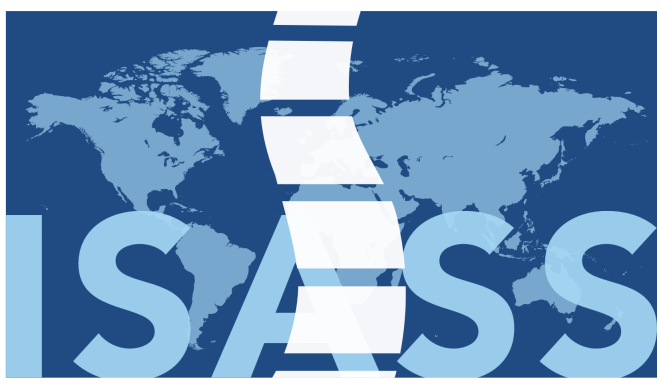

INTERNATIONAL SOCIETY for the ADVANCEMENT of SPINE SURGERY 


\section{Validation and Analysis of a Multi-site MIS Prospective Registry Through Sub-analysis of an MIS TLIF Subgroup}

Joseph A. Sclafani MD,${ }^{1}$ Kamshad Raiszadeh MD, ${ }^{1}$ Ramin Raiszadeh MD, ${ }^{1}$ Paul Kim MD, ${ }^{1}$ Todd Doerr MD, ${ }^{2}$ Farhan Siddiqi MD, ${ }^{3}$ Ivan LaMotta MD, ${ }^{4}$ Paul Park MD, ${ }^{5}$ Cary Templin MD, ${ }^{6}$ Sandeep Gill, ${ }^{7}$ Kevin Liang PhD, ${ }^{7}$ Choll W. Kim MD, PhD ${ }^{1}$

${ }^{1}$ Spine Institute of San Diego, Minimally Invasive Spine Center of Excellence ${ }^{2}$ Spine \& Orthopedic Specialists, PLLC ${ }^{3}$ Trinity Spine Center ${ }^{4}$ Midland Orthopaedics ${ }^{5}$ University of Michigan ${ }^{6}$ Hinsdale Orthopaedics ${ }^{7}$ Milestone Research Organization

\section{Abstract}

\section{Study Design}

Retrospective analysis of multi-site, prospectively collected database.

\section{Objective}

To assess the validity and utility of a prospective spine registry by sub-analysis of patients treated with MIS TLIF.

\section{Background}

The MIS registry is a large-scale, multi-center series of prospectively collected clinical information on outcomes, complications, and adverse events for minimally invasive spine procedures for the treatment of degenerative lumbar conditions.

\section{Methods}

Analysis was performed on the MIS Prospective Registry database. A subgroup of patients treated by MIS TLIF technique was identified. Statistical analyses were performed on pre and post-operative data collected using validated health related quality of life outcome tools. Missing 1-year patient follow-up data was obtained through progressive correspondence modalities.

\section{Results}

Data analysis was performed on 98 MIS TLIF patients ( 56 female, 42 male) with a median age of 64.5 years (range 25-91 years) which were extracted from a total registry population of 478 patients. The one year follow-up rate was $87 \%$. A total of 64 singlelevel, 23 two-level, 3 three-level, and 3 combined TLIFs staged with an MIS lateral 
procedure were included. The primary surgical indications were spondylolisthesis $(27 \%)$, central stenosis $(25 \%)$, foraminal stenosis (14\%), post-laminectomy syndrome (14\%) and degenerative scoliosis $(6 \%)$. The peri-operative blood transfusion rate was $3 \%$. Complications included intraoperative dural tear $(n=3)$, deep wound infection $(n=2)$, superficial dehiscence/cellulitis $(n=2)$. There was a $4 \%$ re-operation rate at the 1 year post-operative time point. Half of patients were discharged within 2 days (range 1-11 days, mean 2.97 days, median 2 days). All patients that were discharged on the first postoperative day $(\mathrm{n}=14)$ underwent a single-level MIS TLIF procedure and had significantly lower pre-op disability index score than those discharged on POD 3-5 (43.7 \pm 15.5 vs. $56.0 \pm 18.3, \mathrm{p}=0.04)$.

Average ODI scores in the subgroup of patients that had reached the one year postoperative time point were 46.5 pre-op $(n=46)$, and 26.2 at 1 year post-op $(n=40, p=$ 0.0001 ). There was significant improvement in VAS scores: pre-operative (back $=6.7$, leg $=5.4, \mathrm{n}=46$ ), and 1 year post-operative (back $=3.2, \mathrm{leg}=1.7, \mathrm{n}=40, \mathrm{p}=0.0001)$. Patients with pre-operative ODI scores greater than 50 demonstrated significant improvement starting at the 6 week post-operative time point ( 24 point improvement, $\mathrm{n}=$ $46, \mathrm{p}<0.001)$. A pre-operative ODI between 35-50 showed significant improvement starting at 3 months ( 15.5 point improvement, $\mathrm{n}=29, \mathrm{p}=0.05)$. Patients with a preoperative ODI score less than 35 had an initial period of increased disability with a trend towards significant improvement by 3 months post-op $(n=20)$.

\section{Conclusions}

Initial findings of the MIS Prospective Registry show patients can be enrolled in a relatively short time period and patient based questionnaires can successfully be obtained through a combination of clinic follow-up appointments and remote correspondence. Outcomes of the MIS Registry MIS TLIF subgroup were consistent with previously published MIS TLIF studies. Sub-analysis of data collected through level-specific patient diagnosis and treatment modalities permits outcome analysis of a wide breadth of spinal conditions and interventions.

keywords: minimally invasive spine surgery, MIS TLIF, Registry, complications, clinical outcome Volume 8 Article 4 doi: 10.14444/1004

\section{Introduction}

Data-driven clinical results are important to accurately assess the effectiveness of reconstructive spine procedures and technologies. These outcome measures are largely collected through randomized, controlled clinical trials or retrospective chart reviews with cumbersome data collection methods. Results obtained by such studies have demonstrated minimally invasive techniques of spine surgery (MIS) result in less intraoperative blood loss, a shorter hospital stay and lower infection rate than traditional open procedures. ${ }^{1,2,3}$, $4,5,6$ However, the usefulness of this data is fundamentally limited due to a small sample size, narrow inclusion criteria and a short follow-up period. ${ }^{7}$ 
The intrinsic limitations of these study designs can be demonstrated through previous investigations of the MIS transforaminal lumbar interbody fusion (MIS TLIF) procedure. Patients treated with MIS TLIF have less need for post-operative blood transfusion, decreased post-operative back pain, and shorter hospital admission time than those treated by open TLIF techniques. ${ }^{8,9,10}$ Several studies have shown MIS TLIF to have significant improvement in 2-year VAS and ODI scores as well as a shorter time to ambulation compared to open TLIF. ${ }^{11,12,13,14,15}$ While the above publications show promising results for the MIS TLIF procedure, their study groups are limited to single-level procedures with straightforward diagnoses. Furthermore, most of these studies collect data retrospectively and the largest prospective sample contains only 42 MIS TLIF cases. ${ }^{11,12,13,14,15}$

The MIS Registry is a prospective, multi-center collection of clinical outcomes, complications, and adverse events of minimally invasive spine procedures for the treatment of degenerative conditions. This study investigates the efficiency and practicality of data collected through a prospective registry. The validity of the MIS prospective spine registry was determined through comparison of MIS TLIF outcomes in the current literature to data obtained through a sub-analysis of the MIS Registry MIS TLIF cohort.

\section{Methods}

\section{Data Collection and Analysis of Questionnaires}

A prospective, multi-center registry was established to collect data using standardized, validated Health Related Quality of Life (HRQOL) tools on patients treated with various minimally invasive spine surgery techniques. Patient data obtained from 17 surgeons at 15 sites of various practice settings were de-identified and electronically entered into the MIS Registry. A total of six questionnaires were used to collect data on the Registry patient population. Overall response rate was calculated for each question asked in the surgeon and patient questionnaires, respectively. Patient outcomes were assessed through Oswestry Disability Index (ODI), SF-12V2, and Visual Analog Scale (VAS) surveys obtained at the pre-op, 6 week, 3 month, 6 month, 12 month and 24 month post-operative time points. SF-12 surveys were collected for all patients but only scored for a randomized subset of patients.

A novel pre-operative diagnosis and surgical procedure table was constructed to allow data collection on a level-by-level basis for each patient (Appendix A). These diagnosis and procedure grids were completed by the operating surgeon and electronically entered into the Registry database. Complications were collected through a distinct, surgeon completed questionnaire. Reportable complications were collected using the Spine Adverse Events Severity System. ${ }^{19}$ 


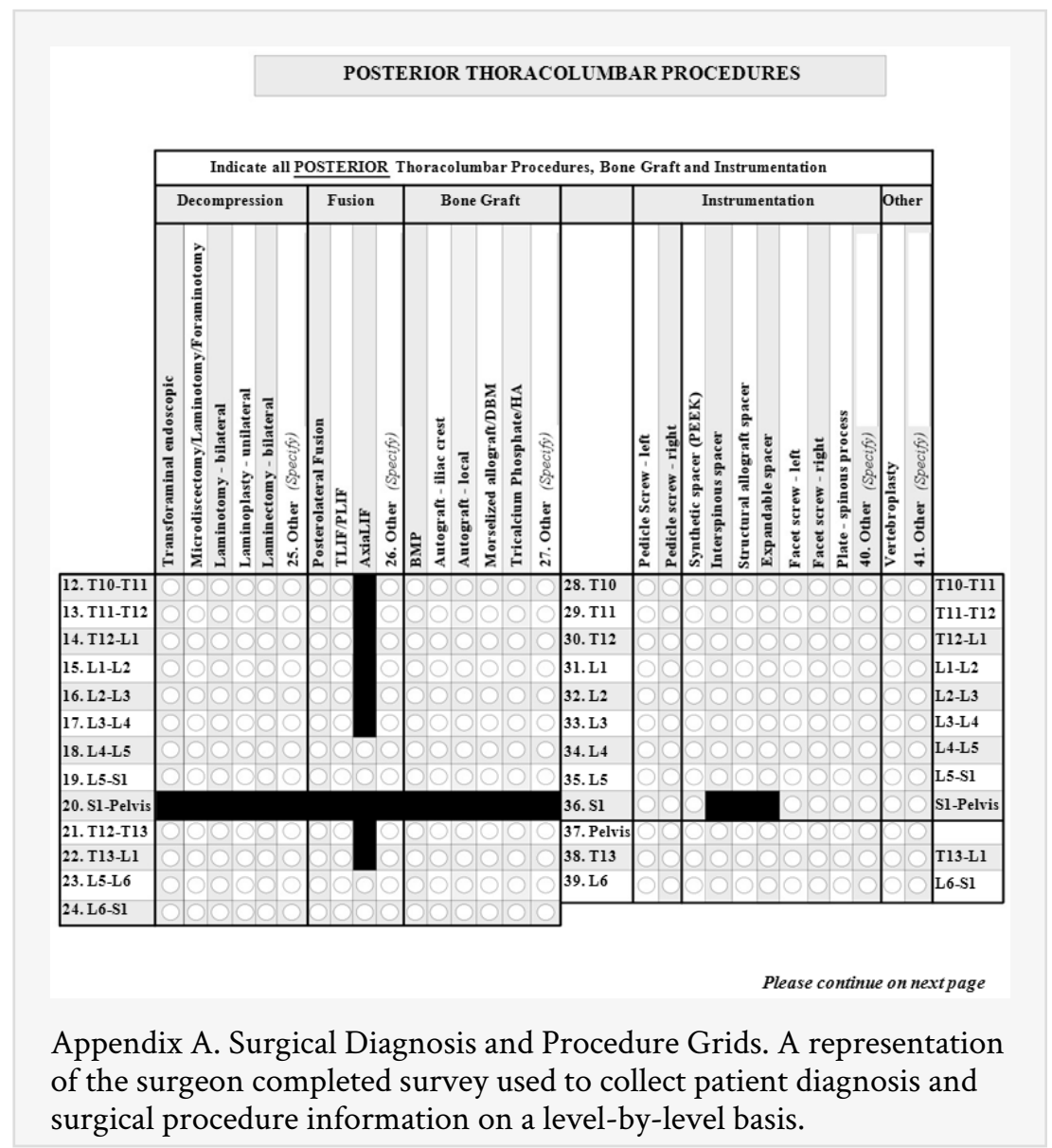

\section{Collection of Missing Data}

Registry patients that were greater than 13 months post-op and did not have complete 12 month follow-up information were identified at the time of database query. A progressive outreach strategy was devised to obtain missing data through correspondence. Responses were collected for a 2 week period after each round of correspondence before attempting further outreach. The initial round of outreach consisted of mailing a blank follow-up questionnaire to each identified patient with a return-addressed postmarked envelope. Secondary questionnaires with a return-addressed postmarked envelope were mailed to patients that did not respond to the initial outreach. Patients were reimbursed with a $\$ 20$ gift card if they returned a completed questionnaire after the second round of outreach. The third round of correspondence distributed an electronic questionnaire via e-mail with a \$20 gift card offer upon receipt of a completed survey.

\section{Subanalysis of MIS TLIF Data}

Analysis was performed on Registry data to extract subjects who underwent MIS TLIF procedures. Data were segmented based on gender, primary indication, operative level, previous lumbar surgery, BMI, co-morbidity and pre-operative pain score for outcome measure analysis of each subgroup. Specific questions within the ODI questionnaire were evaluated to assess post-operative change in walking tolerance (ODI question \#4) and 
employment limitations (ODI question \#8). Statistical analyses were performed via oneway ANOVA or paired t-tests with significance defined as $p<0.05$. Data are reported as means $\pm \mathrm{SD}$, unless otherwise specified.

\section{Results}

\section{Overall data}

A total of 478 patients ( 235 female, 243 male) aged $58.9 \pm 15.2$ years were enrolled in the MIS Registry from April 2011-November 2012. There were 118 MIS hemilaminectomies, 98 MIS TLIFs, 86 transforaminal endoscopic foraminotomy and discectomies, 40 anterior lumbar interbody fusion, 31 microdiscectomies, 22 MIS lateral lumbar interbody fusion (LLIF), and 10 anterior cervical decompression and fusion procedures in the overall registry population. The remaining 65 cases were comprised of MIS interspinous process fixation, vertebroplasty, removal of instrumentation, and dorsal column stimulator placement procedures (Table 1).

Table 1. Patient Enrollment by Procedure.

\begin{tabular}{|l|l|l|}
\hline Total enrolled patients & n & \\
\hline Procedure & 478 & \\
\hline MIS Hemilaminectomy & 118 & \\
\hline MIS TLIF & 98 & \\
\hline Transforaminal Endoscopic Foraminotomy \& Discectomy & 86 & \\
\hline MIS ALIF & 40 & \\
\hline MIS Microdiscectomy & 31 & \\
\hline MIS Lateral Lumbar Interbody Fusion & 22 & \\
\hline MIS ACDF & 18 & \\
\hline Other & 65 & \\
\hline
\end{tabular}

The one year follow-up rate was $86 \%(84 / 98)$ for the overall registry population. ODI scores were $47.1 \pm 16.9$ pre-op $(n=98)$, and $28.8 \pm 21.2$ at 1 year post-op $(n=84, p=$ 0.001 , Table 2 ) in registry patients that had reached the one year post-operative time point. These patients also demonstrated improvement in VAS scores with a pre-operative VAS (back $=6.5 \pm 2.6$, leg $=5.3 \pm 2.8, \mathrm{n}=98$ ), and 1 year post-operative VAS (back $=$ $3.2 \pm 2.7, \operatorname{leg}=1.7 \pm 2.6, \mathrm{n}=84, \mathrm{p}=0.001)$.

Table 2. Clinical Outcomes for the Overall Registry Population.

\begin{tabular}{|l|l|l|l|}
\hline & Preoperative & 1 Year Postoperative & Paired t-test (p) \\
\hline ODI & $47.1 \pm 16.9(\mathrm{n}=98)$ & $28.8 \pm 21.2(\mathrm{n}=84)$ & 0.001 \\
\hline VAS Back & $6.5 \pm 2.6(\mathrm{n}=98)$ & $3.2 \pm 2.7(\mathrm{n}=84)$ & 0.001 \\
\hline VAS Affected Leg & $5.3 \pm 2.8(\mathrm{n}=98)$ & $1.7 \pm 2.6(\mathrm{n}=84)$ & 0.001 \\
\hline
\end{tabular}




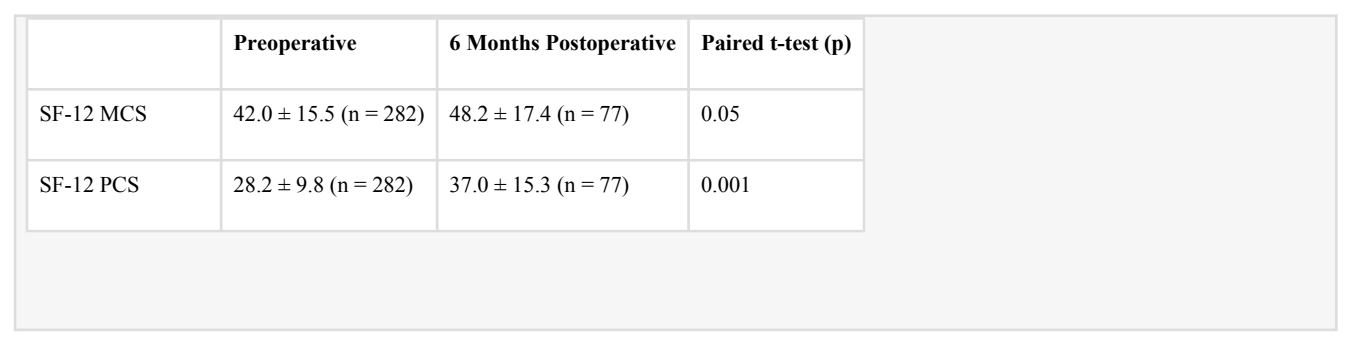

SF-12 PCS scores significantly improved in the overall registry population: Pre-operative (28.2 $\pm 9.8, \mathrm{n}=282), 6$ week post-op $(33.9 \pm 13.5, \mathrm{n}=78, \mathrm{p}=0.01), 3$ month post-op $(34.7 \pm 13.5, \mathrm{n}=116, \mathrm{p}=0.001), 6$ month post-op $(37.0 \pm 15.3, \mathrm{n}=77, \mathrm{p}=0.001)$. Similarly, SF-12 MCS scores showed significant improvement starting 3 months post-op: Pre-operative ( $42.0 \pm 15.5, \mathrm{n}=282), 6$ week post-op $(46.9 \pm 17.4, \mathrm{n}=78, \mathrm{p}>0.05), 3$ month post-op $(49.1 \pm 16.3, \mathrm{n}=116, \mathrm{p}=0.001), 6$ month post-op $(48.2 \pm 17.4, \mathrm{n}=77, \mathrm{p}$ $=0.05)$.

\section{MIS TLIF Subgroup}

A sub-analysis was performed on 98 MIS TLIF patients (56 female, 42 male) with a median age of 64.5 years (range 25-91 years). The one year follow-up rate for the MIS TLIF subgroup was 89\% (40/45). A total of 64 single-level, 23 two-level, 3 three-level, and 3 combined TLIFs staged with an MIS lateral procedure were included. The most common primary surgical indications were spondylolisthesis $(27 \%)$, central stenosis (25\%), foraminal stenosis (14\%), post-laminectomy syndrome (14\%) and degenerative scoliosis $(6 \%$, Table 3$)$. The peri-operative blood transfusion rate was 3\%. All cases of blood transfusion were in multilevel procedures. Complications included intraoperative dural tear $(n=3)$, deep wound infection $(n=2)$, superficial dehiscence/cellulitis $(n=2)$. One year re-operation rate was $4 \%$ including three incisional debridement procedures for post-operative infections and one case of adjacent segment degeneration that required extension of the fusion construct. Half of patients were discharged within 2 days (range 1-11 days, mean 2.97 days, median 2 days). All patients that were discharged on the first post-operative day $(\mathrm{n}=14)$ underwent a single-level procedure and had lower pre-op ODI score than those discharged on POD 3-5 (43.7 \pm 15.5 vs. $56.0 \pm 18.3, \mathrm{p}=0.04)$. ODI scores in the MIS TLIF patients that had reached the one year postoperative time point were $46.5 \pm 15.2$ pre-op $(\mathrm{n}=45)$, and $26.2 \pm 20.4$ at 1 year post-op $(\mathrm{n}=40, \mathrm{p}=0.0001$, Table 4). There was also improvement in VAS scores in this group of patients: preoperative $(\mathrm{back}=6.7 \pm 1.3, \mathrm{leg}=5.4 \pm 2.8, \mathrm{n}=45)$, and 1 year post-operative (back $=3.2$ \pm 2.5$, leg $=1.7 \pm 2.8, \mathrm{n}=40, \mathrm{p}=0.0001)$.

Table 3. MIS TLIF Subgroup Demographic Data. All surgical indications for MIS TLIF are included in the MIS Registry on a level-by level basis.

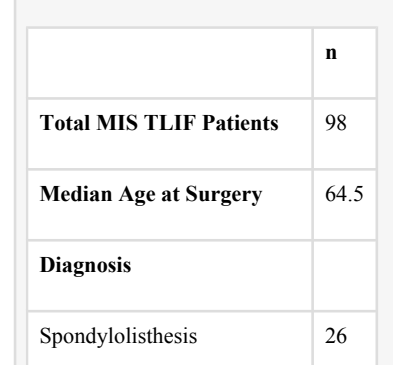




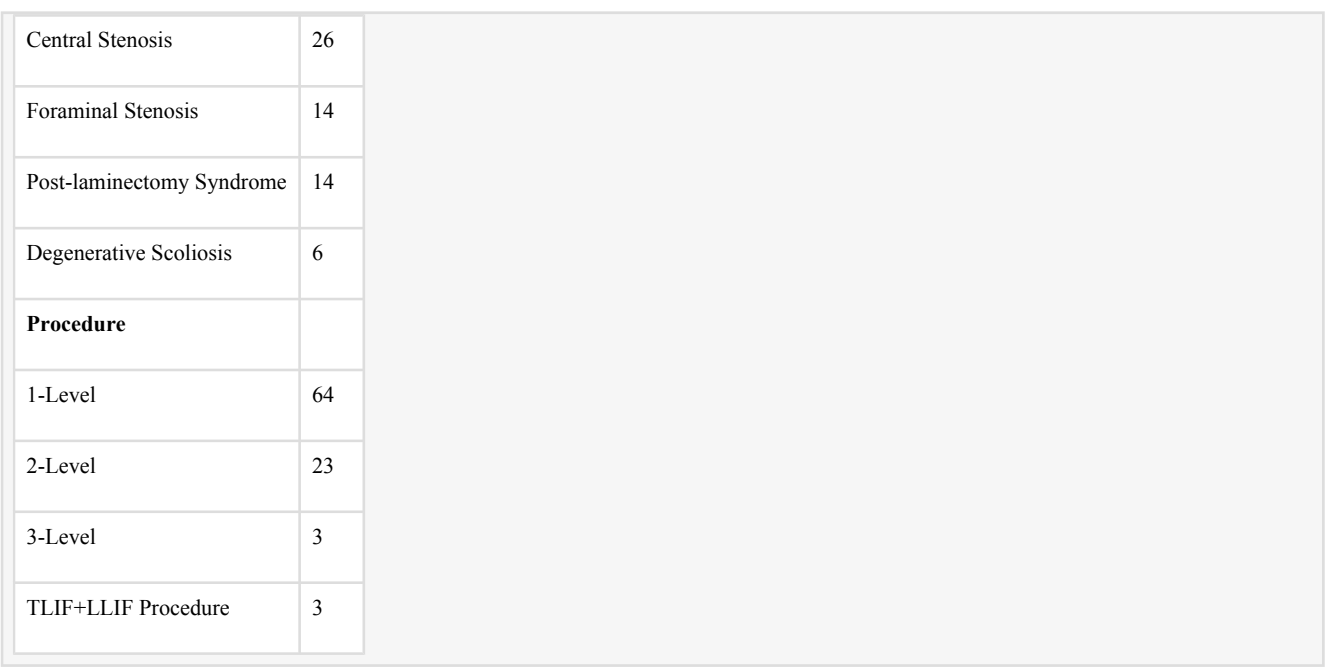

Table 4. MIS TLIF Subgroup Patient Based Outcome Data.

\begin{tabular}{|l|l|l|l|}
\hline & Preoperative & 1 Year Postoperative & Paired t-test (p) \\
\hline ODI & $46.5 \pm 15.2(\mathrm{n}=45)$ & $26.2 \pm 20.4(\mathrm{n}=40)$ & 0.0001 \\
\hline VAS Back & $6.5 \pm 15.5(\mathrm{n}=45)$ & $3.2 \pm 2.5(\mathrm{n}=40)$ & 0.0001 \\
\hline VAS Affected Leg & $5.4 \pm 2.8(\mathrm{n}=45)$ & $1.7 \pm 2.8(\mathrm{n}=40)$ & 0.0001 \\
\hline SF-12 MCS & $41.3 \pm 15.8(\mathrm{n}=87)$ & $50.5 \pm 12.7(\mathrm{n}=34)$ & 0.05 \\
\hline SF-12 PCS & $26.6 \pm 10.7(\mathrm{n}=87)$ & $39.9 \pm 15.3(\mathrm{n}=34)$ & 0.001 \\
\hline
\end{tabular}

Employment disability (ODI question \#8) showed improvement at all post-op time points: Pre-operative $(3.6 \pm 1.2, \mathrm{n}=94), 6$ week post-op $(2.8 \pm 1.4, \mathrm{n}=48, \mathrm{p}=0.01), 3$ month post-op $(2.3 \pm 1.4, \mathrm{n}=73, \mathrm{p}=0.001), 6$ month post-op $(1.8 \pm 1.1, \mathrm{n}=50, \mathrm{p}=0.001), 1$ year post-op $(1.6 \pm 1.1, \mathrm{n}=40, \mathrm{p}=0.0001)$. Similarly, walking disability (ODI question \#4) improved at all post-operative time points Pre-operative $(3.6 \pm 1.2, \mathrm{n}=94), 6$ week post-op $(2.7 \pm 1.4, \mathrm{n}=48, \mathrm{p}=0.01), 3$ month post-op $(2.3 \pm 1.4, \mathrm{n}=73, \mathrm{p}=0.001), 6$ month post-op $(1.9 \pm 1.2, \mathrm{n}=50, \mathrm{p}=0.001), 1$ year post-op $(1.5 \pm 1.3, \mathrm{n}=40, \mathrm{p}=0.001$, Figure 1). 


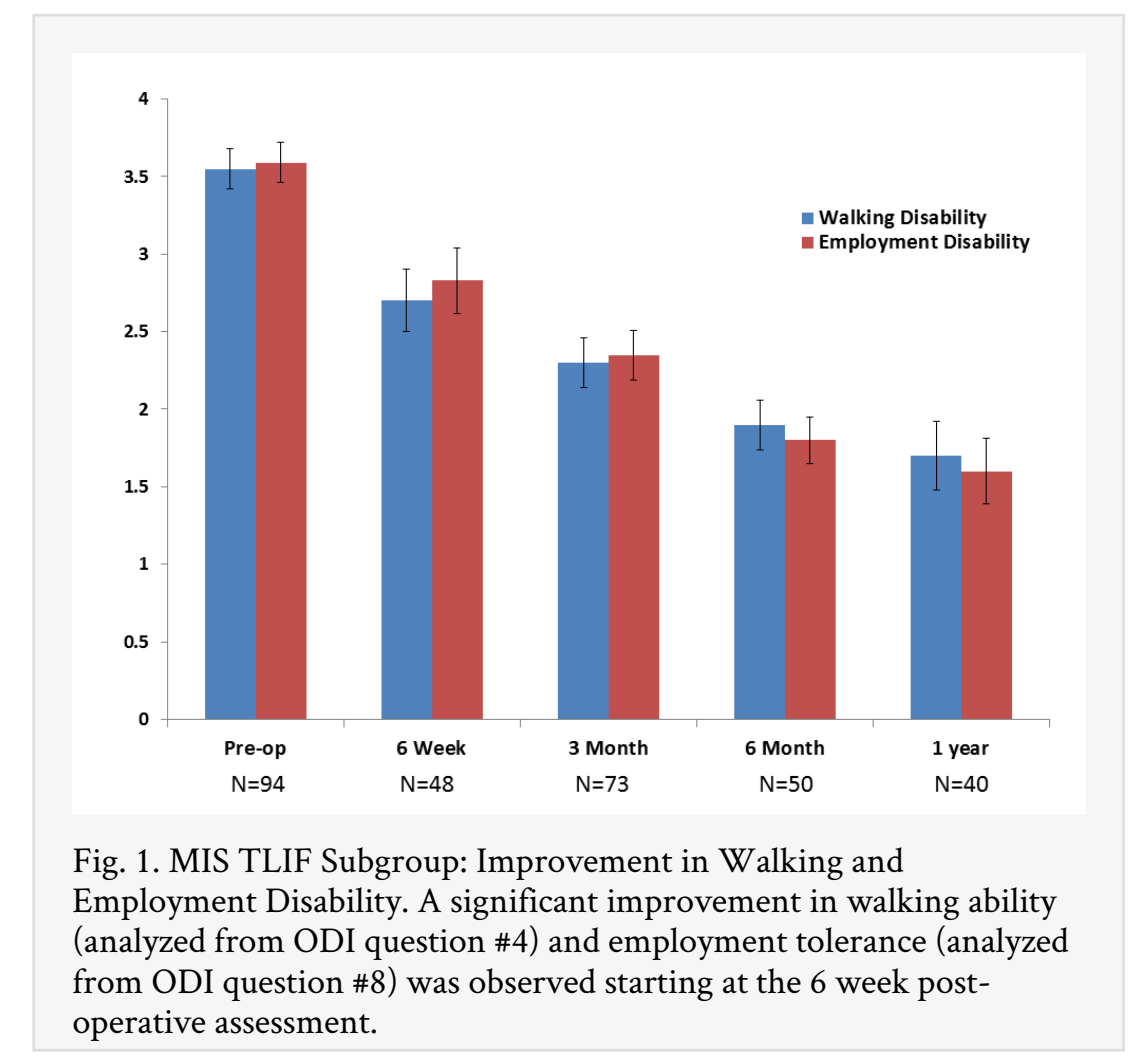

Single-level procedures yielded ODI score improvement starting 3 months post-op (20.2 points, $\mathrm{p}=0.001, \mathrm{n}=64$ ). Two-level procedures resulted in ODI improvement at the 6 month post-op time point (25.8 points, $\mathrm{n}=23, \mathrm{p}=0.05)$.

Patients with pre-operative ODI scores greater than 50 demonstrated improvement starting at the 6 week post-operative time point ( 24 point improvement, $n=46, p<$ 0.001 ). A pre-operative ODI between 35-50 showed significant improvement starting at 3 months (15.5 point improvement, $\mathrm{n}=29, \mathrm{p}=0.05$ ). Patients with a pre-operative ODI score less than 35 had an initial period of increased disability with a trend towards significant improvement by 3 months post-op $(n=20$, Figure 2$)$. 


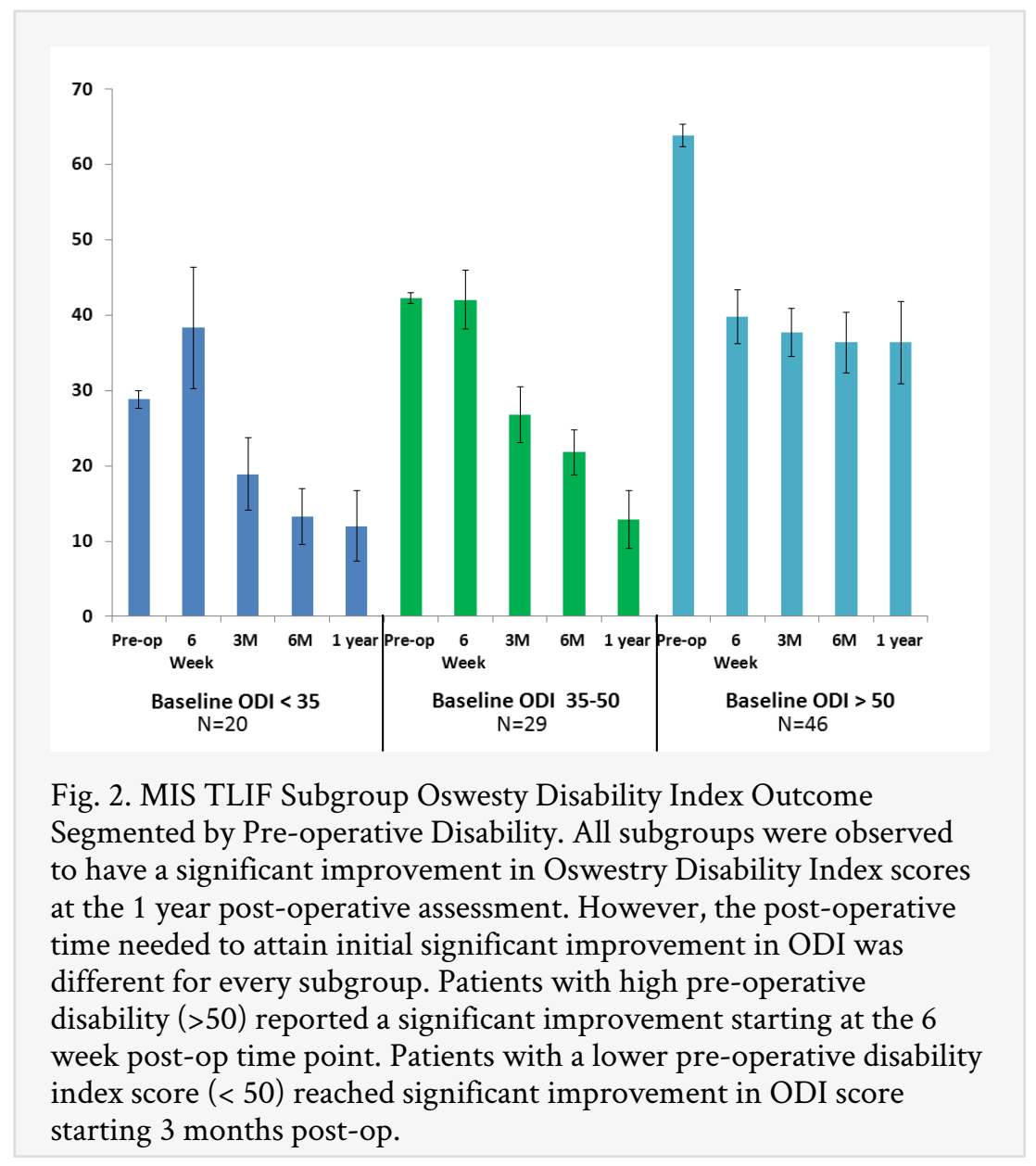

SF-12 PCS scores were: Pre-operative $(26.6 \pm 10.7, \mathrm{n}=87), 6$ week post-op $(28.6 \pm 11.5$, $\mathrm{n}=24, \mathrm{p}>0.05), 3$ month post-op $(36.7 \pm 11.1, \mathrm{n}=48, \mathrm{p}=0.001), 6$ month post-op (39.9 $\pm 15.3, \mathrm{n}=34, \mathrm{p}=0.001)$. SF-12 MCS scores were: Pre-operative $(41.3 \pm 15.8, \mathrm{n}=87), 6$ week post-op $(44.8 \pm 18.7, \mathrm{n}=24, \mathrm{p}>0.05), 3$ month post-op $(51.2 \pm 12.9, \mathrm{n}=48, \mathrm{p}=$ $0.01), 6$ month post-op $(50.5 \pm 12.7, \mathrm{n}=34, \mathrm{p}=0.05$, Table 4$)$.

\section{Analysis of Questionnaires/ Missing Data Acquisition}

Each patient was asked to complete 552 questions (78 pre-op, 79 at each follow-up appointment) and each physician was asked 289 questions per patient (67 pre-op, 37 at each follow-up appointment) over a 2 year cumulative study period. A response rate less than 50\% was observed for 78 patient directed and 24 surgeon directed questions (Figure 3 ). Of the 552 questions asked to each patient, there were 61 questions with duplicate content asked over the 2 year study period. 


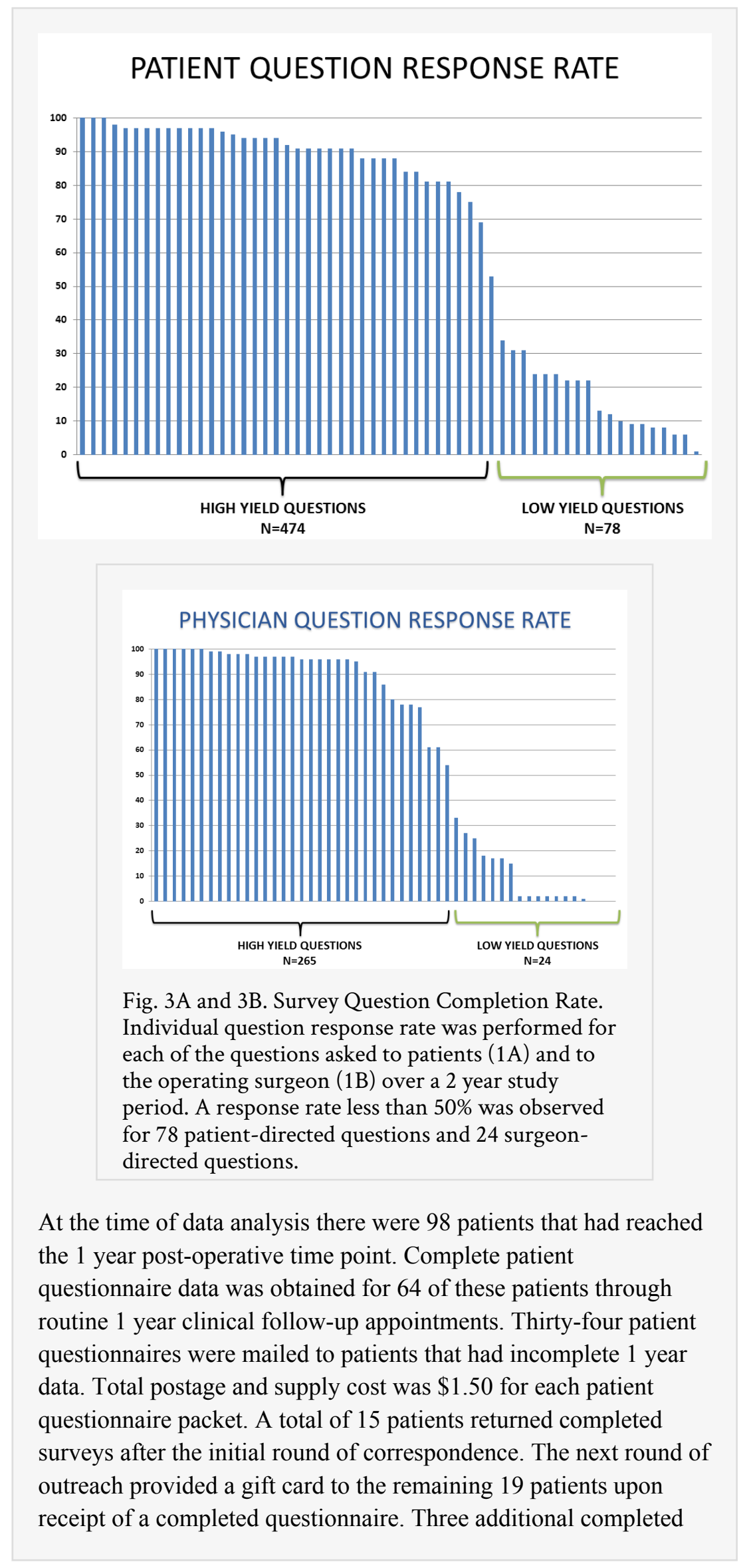


surveys were returned from the second round of US mail correspondence which offered a \$20 incentive. Increasing the incentive to $\$ 50$ via US mail resulted in one further completed survey returned to the study coordinator. Outreach to patients via an electronic questionnaire with a \$20 incentive returned one survey. Increasing the electronic survey incentive to $\$ 50$ did not result in any further surveys returned to the study coordinator (Figure 4).

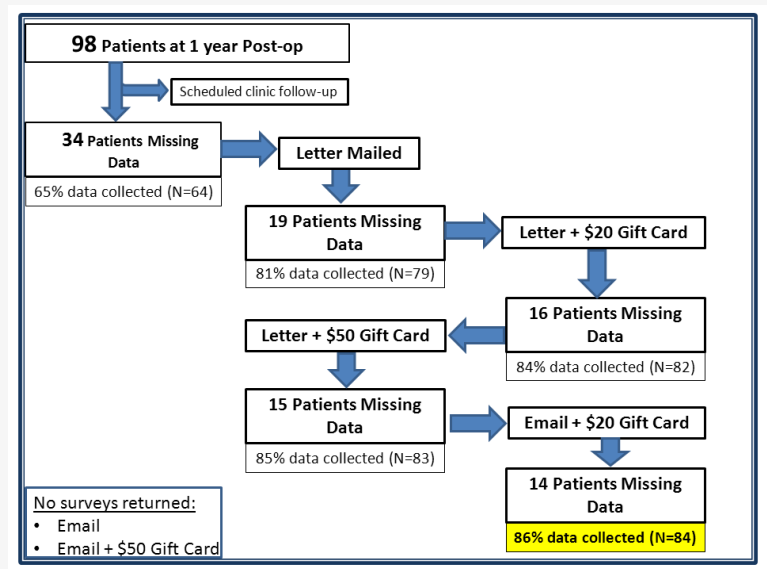

Fig. 4. Algorithm detailing correspondence method used to obtain missing 1 year post-operative followup information. Email based surveys were sent to the remaining patients with missing information without any additional form acquisition.

\section{Discussion}

Response rate analysis of validated, HRQOL modules included in the MIS Registry (VAS, ODI, NDI, SF-12) indicated each question was answered with greater than $90 \%$ frequency. Similar evaluation of overall question response rate in the registry population revealed $14 \%$ of the total patient survey questions and $8 \%$ of physician directed questions were often left unanswered (Figure 3). All questions with a low response rate were initially added to the registry questionnaires to supplement HRQOL survey data. However, these frequently unanswered supplemental questions did not provide meaningful substantive patient outcome information during our evaluation. Additionally, multiple questions within the MIS Registry survey forms provided redundant information to what was already obtained in HRQOL outcome tools. We predict that elimination of duplicate and low-yield questions would facilitate a registry that collects high fidelity data with negligible burden placed on the participating patient and physician. 
Traditional methods to collect patient-based outcome measures rely on comprehensive and accurate form completion during an inperson clinic appointment. Initial analysis of the MIS Registry database discovered complete surveys were not obtained for $35 \%$ of patients at 1-year follow-up during routine office appointments. The ability to capture $59 \%$ of missing patient information through correspondence at a total cost of $\$ 210$ demonstrates this is a viable option of data acquisition. Extrapolation of this cost to a 1000 patient database would deliver complete 1-year outcome data on 860 patients for $\$ 2100$ in addition to Registry management fees. Our attempt to collect missing data through e-mail based correspondence was not successful. However, our method required the patient to print and return the completed questionnaire via the postal service. We hypothesize that e-mail based methodologies of data acquisition will be more successful if the HRQOL questionnaire is propagated in a format that permits completion and submission through an entirely electronic based process.

Initial analysis of the MIS Registry database demonstrates that patients can be enrolled in a relatively short time period to collect clinical outcome information for a broad set of diagnoses and MIS treatment modalities. A significant improvement in post-operative HRQOL measures was observed for the overall registry population after undergoing minimally invasive spine surgery.

Sub-analysis of the MIS TLIF subgroup was performed to compare the MIS Prospective Registry data against previously published studies of MIS TLIF. The average hospital admission time of the MIS Prospective Registry MIS TLIF subgroup (2.97 days) was consistent with previously published studies that reported an average length of stay between 3-10 days after an MIS TLIF procedure. ${ }^{8,9,11,17}$ Previous prospective and retrospective studies obtained a complication rate between $7-33 \%$ and a re-operation rate of $0-14 \%$ which is consistent with the MIS Registry complication rate of $7 \%$ and re-operation rate of $4 \%$ for the MIS TLIF subgroup. $8,12,13,18,19$ No reported complications within the MIS TLIF Registry subgroup were expected to have a prolonged adverse effect on outcome.

Post-operative improvement HRQOL tools such as the VAS, ODI and SF-12/36 have been used in the analysis of several previous MIS TLIF studies to assess procedure success rate. Schwender et al reported a decrease in average VAS back pain (7.2 pre-op to 2.1 post-op) and ODI scores (46 pre-op to 14 post-op) in a retrospective study of 49 patients who underwent single level MIS TLIF procedures. ${ }^{20}$ Shunwu et al found similar improvement in 
back VAS (6.8 pre-op to 2.4 one year post-op) and ODI scores (49.7 pre-op to 22.5 on year post-op) in a prospective study of 32 MIS TLIF cases. ${ }^{12}$ The improvement reported for the MIS Prospective Registry TLIF subgroup back VAS (7.1 pre-op to 3.2 one year post-op) and ODI scores (49.7 pre-op to 26.8 on year post-op) are comparable to the results of previous studies.

Sub-analysis of the MIS TLIF cohort demonstrates that the preoperative disability score is an important factor in post-operative recovery rate. Patients with a high pre-operative ODI value have a significant improvement in function several weeks sooner than patients with low pre-operative disability. This is likely secondary to the effect of peri-operative morbidities such as incisional pain outweighing initial surgical benefits in patients that were highly functioning pre-operatively. Conversely, peri-operative benefits overshadow surgical morbidities in patients with substantial preoperative limitations. This information can be used in the preoperative clinical setting to educate patients about their expected recovery trajectory.

\section{Conclusion}

An optimal prospective registry should function as an invisible entity within the workflow of a busy clinical practice. Our goal was to design an efficient data collection system that avoids placing undue strain onto the patient or surgeon. Initial results of the MIS Prospective Registry show overall improvement in patient outcome measures. Sub-analysis of MIS TLIF patients demonstrates results consistent with previous studies in the peer-reviewed literature. It is expected that enrollment rates will increase with increased surgeon participation in the MIS Prospective Registry. Increased data capture will allow analysis of a variety of spinal conditions which can be subcategorized by level-specific abnormalities and levelspecific treatments to provide information on a wider breadth of spinal conditions. A large registry will make analysis of less common spine pathologies that are not easily studied by traditional clinical trials feasible.

Survey completion and patient follow-up remains a challenging aspect of maintaining a large Registry database. These issues can be addressed by eliminating duplicate and frequently unanswered questions from questionnaires that are completed during follow-up clinic visits. Poor 1-year follow-up can be successfully offset via correspondence techniques that focus on collection of patient based outcome measures. 


\section{References}

1. Oppenheimer, J. H., DeCastro, I., \& McDonnell, D. E. (2009). Minimally invasive spine technology and minimally invasive spine surgery: a historical review. Neurosurgical Focus, 27(3), 9.

2. Kim, C. W. (2010). Scientific basis of minimally invasive spine surgery: prevention of multifidus muscle injury during posterior lumbar surgery. Spine, 35(26S), S281.

3. Jaikumar, S., Kim, D. H., \& Kam, A. C. (2002). History of minimally invasive spine surgery. Neurosurgery, 51(5), S2-1.

4. Kotani, Y., Abumi, K., Ito, M., Sudo, H., Abe, Y., \& Minami, A. (2012). Mid-term clinical results of minimally invasive decompression and posterolateral fusion with percutaneous pedicle screws versus conventional approach for degenerative spondylolisthesis with spinal stenosis. European Spine Journal, $1-7$.

5. Rodgers, W. B., Gerber, E. J., \& Patterson, J. (2011). Intraoperative and early postoperative complications in extreme lateral interbody fusion: an analysis of 600 cases. Spine, 36(1), 26.

6. McAfee, P. C., Garfin, S. R., Rodgers, W. B., Allen, R. T., Phillips, F., \& Kim, C. (2011). An Attempt at clinically defining and assessing Minimally Invasive Surgery (MIS) Compared to Traditional "Open” Spinal Surgery. SAS Journal.

7. McAfee, Paul C. MD, MBA; Phillips, Frank M. MD; Andersson, Gunnar MD, PhD; Buvenenadran, Asokumar MD; Kim, Choll W. MD; Lauryssen, Carl MD; Isaacs, Robert E. MD; Youssef, Jim A. MD; Brodke, Darrel S. MD; Cappuccino, Andrew MD; Akbarnia, Behrooz A. MD; Mundis, Gregory M. MD; Smith, William D. MD; Uribe, Juan S. MD; Garfin, Steve MD; Allen, R. Todd MD; Rodgers, William Blake MD; Pimenta, Luiz MD, PhD; Taylor, William MD. (2010). Minimally invasive spine surgery. Spine, 35(26S), S271.

8. Wang J, Zhou Y, Zheng Z, et al. Comparison of one-level minimally invasive and open transforaminal lumbar interbody fusion in degenerative and isthmic spondylolisthesis grades 1 and 2. Eur Spine J 2010;19:1780-4.

9. Schizas C, Tzinieris N, Tsiridis E, et al. Minimally invasive versus open transforaminal lumbar interbody fusion: evaluating initial experience. Int Orthop 2009;33:1683-8.

10. Karikari, I. O., \& Isaacs, R. E. (2010). Minimally invasive transforaminal lumbar interbody fusion: a review of techniques and outcomes. Spine, 35(26S), S294. 
11. Villavicencio AT, Burneikiene S, Roeca CM, et al. Minimally invasive versus open transforaminal lumbar interbody fusion. Surg Neurol Int 2010;1:12.

12. Shunwu F, Xing Z, Fengdong Z, et al. Minimally invasive transforaminal lumbar interbody fusion for the treatment of degenerative lumbar diseases. Spine 2010;35:1615-20.

13. Peng CW, Yue WM, Poh SY, et al. Clinical and radiological outcomes of minimally invasive versus open transforaminal lumbar interbody fusion. Spine 2009;34:1385-9.

14. Park P, Foley KT. Minimally invasive transforaminal lumbar interbody fusion with reduction of spondylolisthesis: technique and outcomes after a minimum of 2 years' follow-up. Neurosurg Focus 2008; 25:E16.

15. Adogwa, O., Parker, S. L., Bydon, A., Cheng, J., \& McGirt, M. J. (2011). Comparative effectiveness of minimally invasive versus open transforaminal lumbar interbody fusion: 2-year assessment of narcotic use, return to work, disability, and quality of life. Journal of Spinal Disorders \& Techniques, 24(8), 479.

16. Ramersaud YR, Neary MA, White K. Spine adverse events severity system. Content validation and interobserver reliability assessment. Spine. 2010;35:790-795.

17. Dhall SS, Wang MY, Mummaneni PV. Clinical and radiographic comparison of mini-open transforaminal lumbar interbody fusion with open transforaminal lumbar interbody fusion in 42 patients with long-term follow-up. Neurosurg Spine 2008;9:560-5

18. Bagan, B., Patel, N., Deutsch, H., Harrop, J., Sharan, A., Vaccaro, A. R., \& Ratliff, J. K. (2008). Perioperative complications of minimally invasive surgery (MIS): comparison of MIS and open interbody fusion techniques. Surg Technol Int, 17, 281-6.

19. Rouben D, Casnellie M, Ferguson M. Long-term durability of minimal invasive posterior transforaminal lumbar interbody fusion: a clinical and radiographic follow-up. J Spinal Disord Tech 2011;24:288-96.

20. Schwender JD, Holly LT, Rouben DP, et al. Minimally invasive transforaminal lumbar interbody fusion (TLIF): technical feasibility and initial results. J Spinal Disord Tech 2005;18(suppl 1):S1-6.

\section{Disclosures}

The authors have declared no financial disclosures. 


\section{Corresponding author}

Joseph A. Sclafani, MD, Spine Institute of San Diego-Minimally Invasive Spine Center of Excellence.joey@siosd.com

Copyright (C) 2014 ISASS - International Society for the Advancement of Spine Surgery. To see more or order reprints or permissions, see http://ijssurgery.com. 